\title{
Recovery From Bulimia Nervosa Through Near-Death Experience: A Case Study
}

\author{
Janet E. Colli, Ph.D., and Thomas E. Beck, Ph.D. \\ Seattle, Washington
}

\begin{abstract}
We present one woman's story as a paradigmatic healing process that illustrates an attempted suicide, her near-death experience (NDE), and subsequent recovery from bulimia nervosa. Complex posttraumatic stress disorder resulting from childhood sexual abuse provides the most cogent framework for understanding her initial shattering loss of "self," and her subsequent attempts to re-invent herself and to regulate feeling states through bulimia. Her recall of her NDE through regressive hypnosis adds another dimension to her recovery process, and highlights the single most important factor that helped her heal. We see her NDE's teaching about the freedom and responsibility of choice as crucial to her recovery, and we make a case for increased awareness and study of NDEs occurring in the context of eating disorders. Finally, we give consideration to problems inherent in retrospective recollections and recovered memories through hypnotic regression.
\end{abstract}

KEY WORDS: near-death experience; bulimia; eating disorders; posttraumatic stress; suicide; recovery; out-of-body experience; false memory.

Single case studies have lost considerable prestige since Freud's historical precedence. Yet they can provide a solid framework upon which to portray a previously unknown process. A single case study can disclose the process by which a compulsively disordered psyche successfully negotiates healing. The life-threatening medical complications and suicide attempts that are sometimes concomitant with eating disorders may lead to near-death experiences (NDEs). We will

Janet E. Colli, Ph.D., is a transpersonal psychotherapist and consciousness researcher. Thomas E. Beck, Ph.D., is a transpersonal psychotherapist and trained clinical hypnotherapist. Reprint requests should be addressed to Dr. Colli at the Good Shepherd Center, 4649 Sunnyside Avenue North, Suite 341, Seattle, WA 98103; e-mail: becolli@mindspring.com. 
cite various studies as evidence for that claim, and then explore its significance under the rubric of a single case study. We will present one woman's story that illustrates an attempted suicide, her neardeath experience, and subsequent recovery from bulimia nervosa, in order to highlight what may well be a paradigmatic healing process.

\section{Bulimia Nervosa}

Bulimia nervosa and related syndromes have a prevalence between 0.5 percent and 1 percent, though only a minority of those with these disorders present for treatment (Hay, Gilchrist, Ben-Tovim, Kalucy, and Walker, 1998). Binge eating and behaviors to prevent weight gain, such as self-induced vomiting, fasting, or excessive exercise, are typically kept well hidden. Shame, secrecy, and the fear of discovery of vomiting behavior are the low points of an emotional roller coaster, otherwise distinguished by compulsive planning of binge-vomit episodes, whose aftermath leaves the bulimic feeling disgusted and out of control. Though initially used to compensate for unpleasant affective experiences, for all its eventual misery, binge eating is a futile method of avoiding dealing with painful emotional issues.

Most women with eating disorders who seek treatment tend to get better (Herzog, Sacks, Keller, Lavori, von Ranson, and Gray, 1993). One long-term, follow-up study of bulimic women found that approximately two-thirds achieved recovery after an average of 9 years (Reas, Williamson, Martin, and Zucker, 2000). However, critical reviews of outcome studies have highlighted the variety of definitions and measures of recovery within the eating disorders literature, as well as lack of consistent diagnostic criteria, outcome criteria, and length of follow-up (Jarman and Walsh, 1999). When remission was differentiated from recovery on the basis of the probability of relapse, the probability of relapse was found to be substantial for approximately one year after a woman ceased to binge and purge (Field, Herzog, Keller, West, Nussbaum, and Colditz, 1997). The study concluded that bulimia nervosa is a relapsing condition, and that periods of being asymptomatic that last less than one year should be labeled as remissions, not recoveries.

\section{Bulimia Nervosa in the Context of Childhood Abuse}

A history of childhood trauma or sexual abuse is a general risk factor for bulimia nervosa (Hay, Gilchrist, Ben-Tovim, Kalucy, and Walker, 
1998). Complex posttraumatic stress disorder provides a cogent framework for understanding eating disorders as desperate attempts to regulate overwhelming affective states, and to construct a coherent sense of self and system of meaning (Rorty and Yager, 1996). Trauma leads to the dysregulation of the arousal system, avoidance, and the constriction of affect ("numbing"), as one's self and world are shattered. Organizing one's life around regulating internal state changes can thus become the bulimic's entire mode of being. Lacking the development of a coherent sense of self and system of meaning stemming from within, the patient with an eating disorder turns to the culture for direction on "who to be." She finds meaning and purpose by being in control, a state of equanimity manifested by a thin body. Abusive childhood experiences teach that needs and human relationships expose one to potential danger and betrayal. Longer-term, individual psychotherapy and intensive relational work can restore trust in the human connection and provide the safety to examine the trauma. However, rather than just extinguishing certain behaviors, patients must learn to understand underlying state issues, that is, what is causing them to feel this way, what they are trying to accomplish, and how to regulate internal state changes through other means (van der Kolk, 1995). Ultimately, the patient with an eating disorder must leave the world of obsession with food and weight, and learn to negotiate human relationships in order to heal and grow.

\section{Phenomenological Research: What Is It Like Within?}

Despite the focus on behavioral symptoms of bulimics, research indicates that individuals considered "recovered" from the physical and behavioral features of eating disorders often continue to show distorted attitudes to food, eating, and weight. Increasing attempts are thus being made to evaluate psychological and emotional dimensions, including affective instability and low self-esteem, as well as fears about fat, preoccupation with food and appearance, and disturbances in body image. Components of change should also include the social environment, such as social contacts and educational and vocational adjustment.

Yet the phenomenology of the client's experience of change is largely absent from long-term outcome evaluations (Jarman and Walsh, 1999). Research thus does not capture the interpersonal and organizational meanings of recovery that are negotiated during the treatment process (Jarman and Walsh, 1999). Qualitative changes in 
psychological functioning have, though, been highlighted in literature examining recovery from the client's perspective. Factors perceived to have influenced recovery include a feeling of control over the process and pace of treatment, changes in relationships with peers and family, and positive changes in self-esteem (Morgan, 1988).

Forty women who considered themselves recovered from bulimia nervosa participated in semistructured interviews regarding factors they believed related to their recovery process (Rorty, Yager, and Rossotto, 1993). The subjects had averaged 22.8 vomiting episodes per week; 40 percent binged more than 14 times per week during the worst month of illness. The majority of women ( 80 percent) were motivated to recover by the desire for a better life or being weary of having bulimia dominate their lives; finally acknowledging that their eating disorder was a problem or "hitting rock bottom" initiated the recovery process for over half (63 percent), as well as experiencing a significant life transition, such as entering college (60 percent). Most viewed less obvious cognitive features, rather than behavioral components of binging and purging, as the most difficult to change, such as body image and fear of becoming fat.

\section{A Potential Life Threat That Includes Suicidal Behavior}

Healthcare professionals treating bulimics are confronted with physically damaging, self-harming behaviors with potential lifethreatening consequences (Jarman and Walsh, 1999). Inpatients with anorexia and bulimia have been shown to be at risk for medical complications, including severe cardiovascular complications and lifethreatening illness. Five percent of bulimics in one study were found to be severely medically ill, while 34 percent suffered from a significant medical disorder (Hall, Hoffman, Beresford, and Wooley, 1989). Intensive care unit placement was required for 10 percent of subjects with restrictive anorexia, or anorexia alternating with binge/purge behavior.

The high comorbidity of eating disorders with depression means that the risk of attempted suicide is a potential concern, with as many as 60 percent of bulimics reporting suicidal thoughts, and 20 percent attempting suicide (Viesselman and Roig, 1985). John Viesselman and Madelaine Roig, in a study of 95 patients admitted to an inpatient eating disorders program, found major depression in 80 percent of patients; 20 percent had made suicide attempts, and 40 percent of those attempting suicide had made potentially lethal attempts. Patients with bulimarexia, or bulimia with self-induced vomiting, had more 
preoccupation with suicide than anorexics or bulimics. Precipitating factors tended to be the desire to obtain relief from dysphoric or hopeless affective states.

\section{Near-Death Experiences in the Context of Eating Disorders}

Seiji Saito, Kei-ichiro Kita, Cintia Yoko Morioka, and Akiharu Watanabe (1999) reported the cases of three patients with anorexia nervosa, who recovered rapidly after experiencing a life-threatening episode with severe thrombocytopenia. One adolescent experienced cardiac failure, renal failure, and pulmonary edema, which necessitated intensive life support for about 60 days, with hemodialysis and respiratory support with intratracheal intubation. Eating behavior dramatically changed for each of the three patients after the life-threatening episodes, although they did not seem to have any insights about their disease at the discharge interview. No weight phobia or binge eating appeared during their recovering periods. Body weights returned to normal within 6 months after discharge, and were maintained for 2 years. Saito, Kita, Morioka, and Watanabe concluded:

All of the present 3 patients seemed to experience near-death experiences followed by rapid recovery not only physically but also mentally .... [which] might reflect a natural healing process of their psyches, including both body and mind, through the metaphorical death and rebirth experience provided by their life-threatening physical episodes. (1999, p. 118)

Although these authors used the term "near-death experience" in a nonspecific way, we contend that in such cases a closer look is warranted and might indeed reveal classic NDEs. NDEs have been defined as a

distinctive type of dissociative experience in the face of lifethreatening danger, ... in which persons close to death may believe they have left their physical bodies and transcended the boundaries of the ego and the confines of time and space. (Greyson, 2001, p. 368).

However, given the partial loss of memory that occurred when one adolescent was in critical condition, mere questioning might not be the optimal method of inquiry. Janice Holden and Frank MacHovec (1993) thus investigated the benefit that might be gained by hypnotic recall of NDEs, and described procedures to minimize risk that included a hypnosis protocol. Our case study involved just such an experience: 
that is, hypnosis facilitated the recall of an NDE that occurred during an apparent loss of consciousness. This client, too, at the time of her discharge from the hospital, lacked insight about her bulimia.

One study of hospital admissions for attempted suicide reported an incidence of resulting NDEs as high as 26.2 percent (Greyson, 1986). In light of the frequency of NDEs following attempted suicide, further studies are indicated with regard to the effect of such experiences on subsequent suicidal behavior, especially as NDEs have been reported to reduce suicidal ideation. Gary Groth-Marnat and Roger Summers (1998) compared the altered beliefs, attitudes, behaviors and values of subjects who reported having had a NDE to persons who reported similar life-threatening incidents but without NDEs. Results indicated that the NDErs went through a significantly greater number of changes than did the comparison group, including increased transcendental experience and self-worth. Highlighting the compensatory nature of near-death experiences, Kenneth Ring (1991) presented four case histories of experiencers whose lives, prior to their NDEs, were marked by deep despair, including the case of a woman who was sexually abused.

Harvey Irwin (1993) hypothesized that NDErs are characterized by a dissociative response style due to severely traumatic childhood experiences. While his survey study did not identify a dissociative response style, these subjects did evidence a distinctive history of traumatic events in childhood. Ring (1992) also demonstrated a link between trauma in childhood and NDEs. Many survivors of childhood abuse attempt suicide (van der Kolk, Perry, and Herman, 1991). So highly correlated are suicide attempts with childhood trauma, that trauma researcher Bessell van der Kolk (1995) viewed childhood abuse as the greatest predictor of chronic suicide attempts. A nexus thus exists between NDEs, suicide attempts, eating disorders, and childhood trauma. Because childhood trauma is a general risk factor for bulimia nervosa, and because both childhood trauma and bulimia increase the likelihood of suicide attempts, a strong case can be made for increased awareness and study of NDEs occurring in the context of eating disorders.

\section{A Case Study: In Her Own Words}

To elicit what recovery is like from the client's perspective, one of us (J. E. C.) conducted an open-ended interview of her psychotherapy 
client, Amy, who had formerly recovered from bulimia nervosa. The following is Amy's own version of her healing process. As Marcia Rorty and Joel Yager (1996) suggested, complex posttraumatic stress disorder resulting from childhood sexual abuse is the most cogent framework for understanding both her initial shattering and loss of self, as well as her subsequent attempts to reinvent herself and to regulate feeling states through bulimia. Moreover, the factors Amy perceived to have influenced recovery were very similar to Maria Jarman and Susan Walsh's findings (1999): that is, being weary of having bulimia control her life, and finally "hitting rock bottom" in the context of a major life transition to college. However, an NDE, though initially unconscious, arguably became a critical factor that propelled Amy into recovery. Here is Amy's account of the development of her bulimia:

I was sexually abused when I was in the first grade by [a man who, along with] his wife were my parents' best friends for 15 years. I never talked about it, and I think that is when I began pretending for everyone. I didn't want to upset anyone and let them know how hurt, angry, and ashamed I was. After I was sexually abused [7 years old], I stopped being more of an outgoing kind of person, and started being introverted. Before, I had lots of friends, felt really comfortable in school. After the sexual abuse, I didn't want to talk to anybody. It was $90-100^{\circ}$ outside, but I was wearing a big, pink sweater over everything to cover myself. Spandex leggings were "in," which I refused to wear-cause I thought it was too sexual, too revealing. I always tried to cover my body really well .... I was average weight, but I thought I was really overweight. Everyone else seemed so much skinnier. I thought I had a chunky middle, "that just had to go."

I tried to start dieting in the 7th grade. I put myself on a strict diet. The only thing I'd eat for lunch was a piece of bread, a little butterfor one month. That didn't seem to work well enough. One day, I told Mom I was sick, and I stayed home from school. And when I stayed home, I got hungry and was eating. We had talked about eating disorders in school. It just occurred to me to start doing it myself. It worked for them, it could work for me. That day, I put my finger down my throat and threw up my lunch. That worked pretty well.

I started eating whatever I wanted and throwing up. I saved up my allowance money. I'd buy doughnuts and candy bars; I'd fantasize about it. I'd go to Burger King or McDonald's, and blow my allowance, get home before anyone else, and "chuck it all." I was eating way more than normal. My brother was 15 years old; I was out-eating him by 3 or 4 times. My Mom started noticing that I was eating much more than my brother, but she didn't say anything. What happened was my friends at school noticed how much weight I was losing. In a month or two, I lost close to 20 pounds. I'd weigh myself constantly. I was about 98-99 pounds; I'd been maybe 130 - at 5 feet. It wasn't like I looked sick, but it was enough that [friends] noticed that something was 
really different. They went to my teacher, who called my parents. We had this whole intervention thing with my teacher and parents. We all had a chat about it; it was really embarrassing.

My parents brought me to a psychologist .... I'm a really good actress. I threw on all my charm and smiles. I saw her about two times. We were ready to move. She told my parents I was just going through a phase, and that it was over now. My parents thought, "Great! Amy's fixed."

We moved back to [my home town]. I had just started high school. By now, my parents would be watching me if I went to bathroom after I ate. So I would go to my room, and throw up in garbage bags. I'd triple-, quadruple-layer them, so you couldn't smell anything. I'd [use] bathroom spray, and hide them in drawers. I'd get so much vomit, I'd get big, black, heavy bags, and keep them in a huge, Hefty bag in my closet. I'd put them on my bicycle and take them to the dumpster. I came home one day; my dad was in my room and he was crying. He got down on his knees, crying, "Why are you doing this to us?" He had found one of the huge garbage bags of vomit. That was a bad day! Then they were really upset.

[J. E. C.: How often were you vomiting?]

Anytime I would eat something. If I didn't have the opportunity, as soon as I could vomit, I would. I tried to convince my brain nothing was digesting; it was going to wait until I could get it out ...6-10 times a day on average, 'cause I was busy in school with play rehearsal.

They immediately got me a new therapist, who tried some meditation, but I didn't really get what she was doing .... When the therapist started to tell my Mom things I'd said, I decided I was not going to work with her. So for 2 years, I just "faked her out" the whole time. She thought I was doing great! I'd say, "I only threw up 3 times this week, or once this week." I was totally lying. I was really convincing.

What was frustrating was that my parents expected I would stop just because I got caught. That was never going to happen. I'd vomit in the neighbor's yard behind the bush if I couldn't do it in my bathroom. I was normal weight. No one would be able to know. I think what happens is, after a while, your body adjusts to what you're doing. I was maintaining my weight. When I felt really stressed out, I wouldn't eat at all. [Eating] was comforting, so I'd always want to go back to eating. I'd throw up at school, or in the yard, or wherever I could. 'Cause I was going to see a therapist, my parents would not be as watchful ....

I was the kind of person [who, if I had] 5 minutes to get to the next class, I'd be running to the bathroom, fixing my makeup, totally conscious about what I looked like. At home, I had rollers in my hair all the time.

Catapulted by sexual abuse into a hypersensitivity about her image, Amy's strategy to achieve safety and self-worth involved controlling 
that image, as seen from without. As her judgments about her appearance, fantasies, and obsessive behaviors with food became paramount, the divide between her inner reality and outer image deepened. Another intervention followed, this time initiated by Amy. Given her ability to be "fake," this was a tentative step towards facing her problem. She wrote in her journal:

My logic tells me I will never be happy with what I look like, no matter how much weight I lose, so I know that means I need to learn to like myself somehow, but when you haven't for so long, how do you ever begin?

Another therapist was suggested. Yet the significant life transition to college and her poor adjustment to it led to her collapse:

I saw "Claire" [her therapist], the end of my junior year, off and on for about a year. I still didn't want to work [in therapy]. I was still lying and [vomiting]. Then I went away to college. That's when it got worse. I was away from my parents. I missed home and my boyfriend, and he ended up dumping me. Now that I was living on my own, and didn't have anyone watching me, I was just like a kid in a candy store. I'd spend all my money on food. I had a job and I went to my classes, but I could count on one hand the number of times I hung out with friends. I'd get up in the morning, work out in the gym for 2 hours, and then I'd eat and vomit, go to class, then I'd go back to the gym and work out, and then I'd go to my job. Maybe 10 at night, I'd go jogging.

Christmas came; I went home and felt better, and confronted the boyfriend who dumped me. But I went back to school and felt worse. That's when I stopped wearing my makeup and [fixing] my hair. Before, 10 times a day, I was checking myself out. But now, I didn't care. I'm sad and depressed, I'm calling home and crying. My mother had to tell me what to do each day. "Amy, you need to go talk to a counselor at school."

I went to the school counseling office [and was prescribed] Paxil. "Okay, if it will help, sure." I don't really talk to them about what's going on. They give me Paxil and it just makes me "hyper" all the time. I could not relax. I didn't like the way I felt on it, so I stopped [after] a month and a half. I'm throwing up 25-30 times a day. Anything that goes in, it's going out. The more I keep doing that, the more I want to keep doing it. I'm just feeling lousy all the time. I've always been an " $A$ " student. This quarter, I can't even concentrate. I have my Walkman on, listening to African music 15 hours a day, throughout lectures, walking around, not looking at people, not even there. I'm constantly with my habit; that's all I'm doing.

I go home for Spring break. [School] really felt like I was in hell. I just needed to get home. I see all my friends. We have fun. And it's getting close to going back. I'm getting upset about it. I'm getting depressed. One morning, I wake up; I'm always listing things in my 
head of what I've got to do, I'm always planning, organizing. That day I decide that the last thing on my list to do is kill myself. That's just how I decided. It's really weird. I'm probably "checked out" at this point. I'm totally not myself.

Amy wrote the following in her journal while in the hospital, just days after her suicide attempt. Her retrospective analysis ended on a jarring dissociative note. She had indeed "checked out":

Am I just trying to block this experience out like the sexual abuse? .... I am trying to picture myself on Monday ... and get back that feeling I woke up with. I can just remember feeling an overwhelming sadness and loneliness. I didn't start thinking about all of my problems and then say to myself, the only way out is killing myself. I just remember feeling isolated from people, love, my own feelings, and I just said to myself, "No more, I am doing it today." Then I put it at the end of my check-off list in my head for the day and went on about my business .... I am not so sure if it was desperation that made me do it but an overwhelming determination to accomplish a task and execute it correctly and effectively.

Amy continued her account of her suicide attempt:

I go through my Mom's medicine cabinet. And I get the codeine, Percodan, a huge bottle of Tylenol with codeine. I'm thinking, that's not enough. I had gotten liquor the night before-four wine coolers. So I go to Fred Meyer's and buy a razor, two more bottles of Tylenol. I'm ready to go. But I can't be where anyone will find me. I start driving. I don't know where I am; I'm just out of my mind. It's this two-lane highway .... It's really dark and deserted. A big warehouse, there's trees and branches. I take branches and put them on top of the car. I put blankets down on the seat. I had a tape player with a tape of Bob Marley. Then I just start drinking and swallowing pills. Once I'm pretty drunk, I start cutting my wrists. It's not as easy as you might think it is! Yeah, it hurts! I was starting not to feel much then, because of all the liquor and drugs. I was bleeding quite a bit. I wrap myself in the blanket and I just go to sleep.

Amy described her NDE, recall of which was facilitated by hypnotherapy 7 years later:

There is an ambulance on the freeway. It's red. I am above it looking down on it. I can see [the] airport. I follow the ambulance. I hear the siren. I am watching myself. I have on a bright turquoise sweatsuit. I can see them taking off my clothes in the ER. It's disturbing to watch. I feel like I am going into my body.

[When I originally leave my body] I feel like light or energy. My [physical] body is getting smaller. Very tiny. My body-so sad I had to get away from it. My body disappeared. 
She then described being in a different place:

It's very pink .... I'm floating. I don't see myself. I feel happy. There is nothing there, just pink. I feel happy. A voice says, "Can you hear me?" Someone is calling. I hear the voice.

"Do you know who I am?" it asks. "How many times are we going to have this conversation?"

I don't know what to say.

The voice is saying a lot of things to me, like "Why do you choose to create misery?" It talks of my life and choices. I must understand everything is my choice.

Now I am spinning in yellow-a blue place. I see the ambulance. I am a baby again. A voice says, "Bowel movements are okay. Don't think about it."

I'm not dying, after all.

Amy later interpreted her NDE:

When I was talking to the voice, everything was pink and brightand elevated. We were up high somewhere. I can remember leaving my body, and going to talk to this guy, or this voice-whatever. And him asking about why I create my own misery ... meaning that $I$ create. I don't think I grasped that. When you're in this cycle of this habit, you don't see that you're creating it. You just think: this is all there is. And hearing that, I got to understand that I $d o$ get to create.

Amy's NDE emphasized the element of freedom of choice and its self-created constriction. Eating disorders, while demanding perfect self-control, perversely come to control the person herself, who may perceive herself to be helpless. The following entry from Amy's journal, written while in the hospital, is indicative of this:

I feel overweight and unattractive. But it is controlling my life and has been very time consuming. I cannot remember what my life was like without throwing up.

Conversely, a total loss of control may initiate recovery. This was the case for an adolescent anorexic whose medical collapse and admission to the neurological intensive care unit with hypophosphatemiainduced Guillain-Barré syndrome was precipitated by an aggressive refeeding schedule through a nasogastric tube. As she expressed it: "I don't ever want to lose control like that again" (Miller, 1993, p. 493). According to her treating psychiatrist, "This experience, however, enabled her to realize that she really would die if she did not fight her anorexia" (Miller, 1993, p. 496). The power of life or death was thus placed in her own hands.

Such a dynamic highlights the single most significant insight gained during Amy's NDE: "I can create." Factors perceived as crucial to 
recovery, such as learning to regulate internal state changes through other means and exercising control over the process and pace of treatment, can be seen as variants of that insight. "Everything is my choice," not just "eating and throwing up." Would Amy continue to create misery by clinging to the cycle of her habit and a negative selfimage, or would she exercise her newfound freedom of choice?

Yet Amy's was a complex case. She did not initially recall her NDE. Can an NDE, though not in conscious awareness due to its altered state nature, nonetheless exert an effect on the life of the individual? We contend that the expressed meaning of Amy's NDE resounded throughout her recovery process. Amy thus began to enact her NDE's teaching by her decisions to stop seeing visitors and to check out of the hospital, and to restrict her food intake instead of "eating and throwing up." The power that she slowly but surely gained to exercise healthy choices continued to grow as she assumed responsibility for her life:

When I wake up, the next thing I know, there's charcoal coming out of every orifice. I'm in the emergency room, and there's people everywhere, they're cutting my clothes off. When I went through the hypnosis [7 years later], I could feel my bowels giving out. So I thought, "Oh, I'm dying now." The [doctor] is up there, "Keep breathing, keep breathing," but I'm trying not to breathe. "Come on, breathe!" I'm not going to do it.

[A few days later] the doctor, he comes in, and I had a lot of talks with him. He was a really cool doctor. He told me when they found me, "Your heart had already stopped." The way I was found was, some guy, who'd never been walking that way before, decided to go for a walk that morning. And he happened to see the car and called the police, and stayed with me until they came .... [The doctor] started screaming, "Do you understand, you're so lucky to be alive!" But I don't want to be alive. He tried to explain how, if that guy hadn't been there, I wouldn't be here right now.

My room was full of gifts; church ladies would come [and ask], "Why did you do this?" I told them I didn't want any more visitors. They don't know me; I'm not the person they think I am. 'Cause I portrayed this really smart, perfect person who had all these interests, and was in all these activities, president of all these clubs, and that's not who I really was; I was really miserable. So I told them, "No more visitors."

The following entry from Amy's journal was written in the hospital:

I feel guilty and bad when people give me things because I tried to kill myself. I needed to die to escape the misery, and people are showering me with cards/gifts that I do not feel worthy of. It makes it difficult to live with myself. 
Amy continued her narrative:

I stayed in a psych ward for a couple of months. Even though it was voluntary, I didn't think I had much choice. I sure didn't want to go home to my parents. Every morning, I got up two hours before everyone, so I could look perfect. I had the nurse at the station wrap my arms in plastic bags to take a shower, 'cause they couldn't get wet. I'd cut tendons. You got to order what you wanted, so I'd order the lightest possible meal on the menu, and go throw it up.

Then one day, the nurse tells me I need to stop throwing up. I was like, "Okay, sure. You're so right!" But of course, I didn't really mean that. I was really irritated. They would follow me; they'd be knocking on my bathroom door: "Amy, what do you think you're doing?" So I left [after two months] because they weren't going to let me throw up anymore.

Amy clearly felt pressured to commit herself to stay on the psychiatric ward. Though voluntary, she "didn't think [she] had much choice." And being closely monitored was also evidently not her choice. Given an NDE that stressed choice and personal responsibility, this course of action was limited in its effectiveness. But opting to leave the hospital was soon within her power.

The dissonance between inner and outer reality is another central theme in the eating disorders complex. However, in light of a suicide attempt and an NDE that reflected her misery, this dissonance was becoming painfully obvious to Amy. Though still concerned with her physical appearance, she allowed herself, perhaps for the first time, to feel "miserable," and not portray "a really smart, perfect person." Though not yet ready to change her eating-disordered behavior, she soon would be:

I starting seeing the last therapist, Claire. This time, I had to start working [in therapy] 'cause I wasn't dead, and I had to fix things. I'm living at home with my parents, got a job, started doing theater again. I was still throwing up, but it wasn't 30 times a day; it was more like four or five. A pretty big difference. I would go see my therapist every week .... We really didn't work a whole lot on [bulimia].

Then I decided to move in with this guy for seven months. That went sour. He went to New York, and my parents moved. I was completely alone, [had] nobody. When I'm not at community college, or [at work], I'm at home smoking cigarettes, and watching videos over and over again, 20 times. That's when I went through a period of not eating. I just ate cream of wheat for three months .... I didn't throw up that much, maybe three or four times a week. 'Cause I'm depressed. The change then was, when I was depressed, instead of turning to food, I decided no food-which was very different from 
before when I was depressed, I'd eat and throw up. Actually, I felt a little power from that.

As the phenomenological research bears out, choice-a feeling of control over the process and pace of treatment-appeared to be a crucial element in Amy's healing process. Even the minimal element of choice involved in her decision to fast, instead of "turning to food," proved to have healing potential. The little bit of power or self-motivation Amy felt from that choice proved to be a step in the right direction. Clinicians working with this tenacious and deadly illness may well be struck by the ease with which Amy claimed her purging decreased, from 30 times a day to 10 times a month.

Then I coasted along. I really started working with the therapist 'cause I had no distractions. She saw that I can be completely fake with people and act like a clown, really outgoing .... I didn't know who I was.

An entry from Amy's journal echoed this theme:

Being myself-I feel like I am acting most of the time. I am often afraid to express my true feelings because I don't want to hurt anyone and I am afraid that others will disapprove of an unhappy person to be around.

Her narrative continued:

I had to teach myself how to make friends. We would do these things like, the first week I was at school, I'd make eye contact. That was the best I could do. The next time, [I'd] smile. Every week, something really small. That took about a year, and by the end of the year I had friends .... I'm eating-salads mostly at this point, light food. I'm throwing up at least three to five times a week, but not every day. Sometimes, all on one day. But it's still there. So I'm there for another year by myself. I would go to Step Aerobics everyday ....

I'm 22. I'm probably throwing up, maybe 10 times a month. It's not every day, every meal. I'm working three jobs and going to school, and that's when I start smoking marijuana. When I start smoking marijuana and cigarettes, the throwing up really started going away .... I think it's obvious that before the suicide attempt ... I did not see a way out, except to kill myself, literally. And after the suicide attempt, it was so different. To me, it seems a natural progression. It just kind of tapered off, without me doing a lot of work. I really wasn't focusing on trying to stop at all. I wasn't. It was more, me talking about other things with the therapist, and that just kind of fell away.

But I wasn't thinking, I'm not going to throw up today .... I think what was helpful was that, when I went to see Claire, I could tell her I was doing it [purging]. I didn't have someone watching me to stop doing it. And so when everyone wasn't focused on Amy's problem, 
Amy's problem wasn't the focus of my life anymore. It was more like, all the things that were really upsetting me became the focus. And that started to fall away. But when someone is saying, you can't do this, then you're like, I have to hide this. And when I didn't have to hide it anymore, it wasn't like I had to. Maybe that's what I have to do with my smoking! I guess I just have to work through this naturally. I also think I took on some other addictions to replace it, too, like the smoking and the drugs. Those replaced [bulimia] too, gradually.

However, although Amy's struggle with "some other addictions," from tobacco and marijuana to work, continued, she was functioning on a higher level. No longer burdened with a potential life threat, such behaviors were becoming increasingly less harmful as she learned to deal with the underlying issues:

You feel so happy all the time when you're high. My brain went, "New ideas, new ways of thinking. Why am I going to school?" I called my parents and told them I'm quitting school. I'm going to work for [a software company]. Then I was working maybe 60 or 70 hours a week in product support .... I wasn't throwing up hardly at all, maybe a couple of times a month. I had a new boyfriend, "Andy." When I had my car accident [age 25] is when things started to really pick up the pace in my whole spiritual thing.

As Amy's educational and vocational issues resolved, the articulation of the spiritual realm came into focus and her recovery process diverged. It is not that spirituality plays no role in the recovery process of bulimics: many of the 38 percent of recovered bulimics in one sample who utilized Overeaters Anonymous appreciated its spiritual aspects (Rorty, Yager, and Rossotto, 1993). Twenty-five percent received other forms of nonprofessional care, such as spiritual guidance. But it is likely that recovered bulimics who report NDEs will experience a significantly greater number of changes than those without NDEs, including transcendental experience and an enhanced awareness of paranormal phenomena. At this point, presumably, the spiritual effects from Amy's as yet unconscious NDE, began to make themselves known:

The car accident [age 25] made everything stop at work, and I wasn't go, go, go. I had to stop all that. And I've never been that busy since. Since the car accident, work is not my first priority. Everything else is. [The car accident was] a catalyst.

Right after the car accident, this voice in my head started saying, "You need to start meditating." And I see this meditation class flyer, and I'm like, "We should go do this, Andy," and I call and register us. And we never go. That's when we did the "E" [ecstasy]. When I took that, that's when I saw the visions. It was the first time that I 
understood what it meant to feel truth instead of reason it. It was a really big realization .... Before, I wasn't feeling my body with the bulimia and just trying to avoid it. Somehow, after the car accident, I started to feel things again. When I did the " $E$," it just kind of culminated.

Amy's inability to feel her bodily or emotional feelings was a selfidentified problem that led to her attempted suicide. She wrote in her journal:

Sometimes I have difficulty understanding what I am feeling. Even though I was sad, I think I felt that way for so long that I did not comprehend how sad I truly was-for example, I never thought I was suicidal .... I don't cry hardly ever. I am so use [sic] to pretending, that it is no longer a conscious decision sometimes. It is just an automatic response, and I don't realize I am hiding my true inner feelings with a happy mask.

Finally, inner and outer reality became one, in an altered state experience that allowed Amy to "feel truth." Its realization, though drug-induced, cannot be overemphasized. Yet it was the culmination of years of change. And the ensuing transcendental experience, complete with a being identified as her "higher self," consolidated Amy's focus onto unearthly, spiritual realms:

I was in my room, in my bed, and I look up and I see a vision ... of my higher self, that guy. He's on my ceiling and he's got a rectangle of little blue dots around him, and he's got this white robe and white hair, just beautiful. And then disappears. So I looked at Andy and I saw all the spirits and creatures that made up —attached to his body-like all the things that were holding onto him. They were, like, part of his body. And they were part of the blanket on him. It was energy.

Conceivably, "that guy" hearkens back to the entity or voice of otherworldly origin perceived during Amy's NDE. Indeed, an NDE just beneath the threshold of consciousness due to its altered state nature may require a similar altered state, induced by hypnosis or drugs, to initiate its recall: "Information acquired in an aroused or otherwise altered state of mind is retrieved more readily when people are brought back to that particular state of mind" (van der Kolk, 1996, p. 292). Such encoding is termed state-dependent memory. Accordingly, Willis Harman, the late president of the Institute of Noetic Sciences, wrote of the delayed recall of his out-of-body experience, one of the most significant events of his life:

Not only had I "forgotten" one of the most profound experiences of my life, but during that period [4 years] I never had the slightest hint of 
a missing memory, was never bothered by the nagging feeling of something forgotten. There was no clue or sign of a mislaid memory until the triggering incident suddenly brought it to light. (Harman and Rheingold, 1984, p. xv, emphasis added)

Could Amy's ecstasy-induced experience have derived its significance from its being an altered state similar to her NDE? What was triggered in her case was not the memory of the NDE itself, but rather the effects of a certain level of awareness: that is, the ability to perceive entities that seem to be of otherworldly origin. Perhaps when one is initiated into a transcendental level of consciousness, other altered states reflect back to the initial experience, whose impact seemingly reverberates throughout the psyche. In any case, her altered state breakthrough initiated an accelerated spiritual phase of her life:

I saw all that and I made a decision. I can't do "E" every day of my life, or I'll die. It's only that I believe this pill will make me feel that way that it's happening. There must be another way to do that without drugs. Then I said, "I've really got to meditate." My therapist, Claire, had done Transcendental Meditation. Maybe I should .... Right after I came out of my first class [24 years old], I walked into Target and found the Gary Zukav book that totally changed my thinking, and propelled me to read everything on New Age and self-help and spirituality.

Then I met you [J. E. C.] when I turned 25.

In Amy, her psychotherapist (J. E. C.) recognized what Stanislav and Christina Grof termed a process of spiritual emergence (Grof and Grof, 1989). Amy was experiencing both a spiritual crisis and an opportunity to rise to a new level of awareness as she faced her addictive behaviors. An accelerated period of psychospiritual growth followed. As for her bulimia, as the following will attest, her recovery had stabilized:

Now I [purge] maybe once every other month. Only when I feel like I totally splurged. I was smoking pot pretty heavily ... and then when I met you [J. E. C.] I started getting off that. So this last year, I've maybe thrown up eight times in the whole year. And now I exercise in a healthy way. I really don't worry about eating as much. There was one period of time, I would only eat if it was something I really like .... Now I do pretty good. I try to eat really healthy ....

[J. E. C.: So you don't have to fight the impulse at all to binge and purge?]

No. The most interesting thing that's different is that, when I was throwing up so much, I did not understand what it meant to feel. And now, if I'm eating something, I have to stop when I feel full. But 
before, I would never feel full, so I would keep eating. And then I'd feel guilty about it and have to throw up. But when you feel full, you know when to stop. So that was the big change ....

[J. E. C.: Would you say, "I am recovered, but I still struggle with food, weight and/or body image," or, "I am recovered; I no longer struggle with food, weight and/or body image"?]

The first one. I feel there is still an impulse to be thin. There is still an impulse to be afraid to be fat. But what I find myself saying some days-like, when I first started swimming, I went for an hour, every day. But now I notice a change where I'll say, I don't have to go swimming. Why do I have to go swimming when I feel like being at home? Where before, it was like, we failed the day because we didn't exercise. And I start to recognize a difference when I need to go swimming or exercise, because I'm afraid, or because it's fun. There's a difference.

Victims of chronic abuse who have been traumatized prior to their NDEs, as Amy was, may well follow a gradual course of recovery (Colli, 2003). Indeed, victims of chronic abuse may even continue to suffer from the intrusive memories or "flashbacks" that indicate posttraumatic stress disorder. NDEs do not constitute a "miracle cure" for the effects of chronic abuse. Their psychospiritual growth, albeit accelerated relative to those without NDEs, may well appear less dramatic or spiritual than those reflected in the professional literature on NDEs. However, that literature has not yet tended to focus on those whose NDEs happen in the context of chronic traumatization, such as childhood sexual abuse, eating disorders, and domestic violence. How does their healing process unfold? Case studies such as Amy's can elucidate the fundamental changes of perspective that, step by step, lead to hope and change.

\section{A Near-Death Experience in the Context of an Eating Disorder}

Amy's recovery from bulimia nervosa may well be a paradigmatic healing process. Her detailed narrative account accords with preliminary research findings on what recovered bulimics believe facilitated their recovery (Morgan, 1988; Rorty, Yager, and Rossotto, 1993). Moreover, the course of her eating disorder was striking in its context of childhood sexual abuse, its severity and life-threatening consequence, and its ultimate successful conclusion. Amy's recovery progressed from vomiting 25 to 30 times a day at the time of her suicide attempt at age 19 , to about 10 times a month at age 22 , to 
throwing-up "hardly at all, maybe a couple of times a month" at age 23 , to "maybe once every other month" at age 27.

While studies differ in diagnostic criteria and the definition of recovery from bulimia, relapse has been defined as at least four consecutive weeks of binging or purging two or more times a week (Field, Herzog, Keller, West, Nussbaum, and Colditz, 1997). By age 23, given this definition of relapse, Amy could have been considered to be in remission, or above the clinical threshold of what constitutes relapse. She could even, by some standards, be said to have achieved full recovery, as defined by at least eight consecutive weeks at a Psychiatric Status Rating level of 1 or 2 , with 2 indicating that the patient does not meet diagnostic criteria for bulimia nervosa even though she still feels she has to fight the impulse to binge (Herzog, Sacks, Keller, Lavori, von Ranson, and Gray, 1993). Furthermore, Amy's recovery process of approximately four to five years was arguably significantly faster than a nine-year time span in which approximately two-thirds of bulimic women achieve recovery (Reas, Williamson, Martin, and Zucker, 2000), especially as psychiatric symptoms found to be predictive of negative outcome in bulimia include suicide attempts (Herzog, Sacks, Keller, Lavori, von Ranson, and Gray, 1993).

Yet with the advent of Amy's recall of her NDE, another dimension can be added to her recovery process, which serves to highlight the single most important factor that helped her heal. Amy did not initially recall her NDE. The following relates how she came to utilize hypnosis to access the traumatic memories surrounding her suicide attempt:

\section{[J. E. C.: How did you get the idea to do hypnosis?]}

I don't know. I think when I went to get hypnotized to stop smoking, it made me start thinking about that. And how I just started to get into all this spirituality stuff this past year and a half. I think also talking to you about, how you said it takes 7 years sometimes after a NDE [to integrate it].

Not knowing that Amy had had an NDE, I [J. E. C.] had used NDEs during a previous psychotherapy session as an example to explain that life-threatening episodes often take years to integrate. Amy's narrative continued:

I was like, well, it's really interesting I happened to ask her exactly 7 years after it happened. Oh, that's kind of interesting! That kind of got me thinking about it. I think in a way, I had been just trying to get past it. Then I wanted to be able to use it. Now that I'm thinking differently, I want to use that to move forward, and not just try to run 
away from it. And I went, "Oh, I need to find out what happened to me!"

[J. E. C.: I know I didn't think you'd had [an NDE] at all. It never occurred to me. What do you remember from it?]

I remember-I guess the most significant part I remember is being able to see them take me to the hospital. And being able to see them take care of me when I got to the hospital.

[J. E. C.: Where were you in relation to your body?]

I was out of it. I could see it. I also remember when I got back into my body, I was looking at the [doctor] with blue eyes asking me to breathe. I remember going back in.

Two important considerations arose about the use of hypnosis. First, the hypnotherapist must be careful not to use leading language. Second, Holden and MacHovec (1993) emphasized the importance of instructing subjects not to experience the physical effects of an NDE during regressive hypnosis, lest they re-experience physical complications. The following technique used with Amy worked equally well in achieving the requisite distance in perspective.

In the hypnotherapy session conducted by one of us (T. E. B.), Amy was asked to consider her entire life as a continuous movie on videotape. The use of an imaginary videocassette recorder remote control was employed to facilitate regressive and progressive movement through time. Amy was then asked to go back to the last moment she recalled before losing consciousness in the car. She was to slow down the videotape and pay close attention to what, if anything, happened next. Typically at this point, forgotten details-unsolicited by the practitioner-may re-emerge, as was the case with Amy. However, what was atypical with Amy was that she recalled the event as if viewed from an out-of-body perspective; most subjects recall events from a participant's perspective.

Amy described having been influenced by her NDE, even before she recalled the experience through hypnosis:

It's interesting, 'cause I didn't remember talking to ["the guy"]didn't know any of it happened until recently, when hypnotized. But for some reason it was still kind of working. It still really changed me quite a bit.

[J. E. C.: But you think somehow it was affecting you?]

$\mathrm{Oh}$, yeah! It had to have been, because if it hadn't affected me, once my boyfriend left me, I probably would have gone back into the same thing. And even when that choir director dumped me, I didn't go get worse. Because before, when I had a boyfriend in high school, if I felt he was rejecting me-all that stuff I'd say to myself, like I didn't look good enough-I didn't think that anymore. I just thought, "What 
a jerk he is!" instead of, "What is it that I did? What's bad about me?"

I wasn't thinking that as much as I had been before.

When preliminary observations are made about the psychological changes and healing process of victims of chronic abuse who have had an NDE, their healing process appears to be both similar to and different from trauma victims who had not had an NDE (Colli, 2003). In the face of unconditional love and assurance that "I am okay, it was not my fault," near-death experiencers gain the courage to move the external locus of control to an internal locus of control, whenever possible. Exercising whatever freedom of choice is available becomes paramount. That aspect of the healing process is similar to healing in other abuse victims (van der Kolk, 1999).

However, the healing process appears to be accelerated in NDErs. For these individuals, the NDE's revelation that "I am okay, it is not my fault" is a dramatic enough change, and brings about significant transformation. Though it cannot be stated with certainty, it is likely that years of self-abuse had been circumvented for Amy; we thus stress the shortened time span of Amy's remission/recovery. "What a jerk he is," in the context of a life of self-abuse, conveys compassion for herself, a necessary step in Amy's psychospiritual growth.

Finally, two considerations deserve mention. Retrospective recollections may be subject to recall bias, whether intentional or not. Overcompliance with the perceived views of one's psychotherapist may also give rise to misrepresentation. However, bulimia was no longer an active issue in Amy's therapy, and her very recovery placed her in a category less likely to distort. Given that recovered patients exhibit decreased defensiveness about this disorder, researchers tend to credit their subjective accounts of recovery (Rorty, Yager, and Rossotto, 1993).

Secondly, there is no question that what Amy recalled constituted an NDE. Her score was 12 points on the NDE Scale, on which 7 or higher establishes the presence of an NDE (Greyson, 1983). However, an NDE whose memory was recovered during hypnosis raises the concern that a false memory could have been created. Special care was thus taken to avoid leading language during hypnosis. Nor had Amy read any accounts of NDEs prior to hypnosis. Though one of us (J. E. C.) had imparted the finding that NDEs, the paradigmatic example of life-threatening episodes, may take years to integrate, the content of NDEs was not explored in therapy. Yet not only did Amy's NDE contain classic elements, such as leaving the body and existing outside of it, and a definite being or voice of otherworldly origin, but 
significant content specific to her eating disorder was revealed. Of equal importance are the significant life effects that seemingly resulted, which are consistent with changes typically induced by an $\mathrm{NDE}$, specifically the spiritual aftereffects. In this case, it is our opinion that undue importance need not be given to the concern that a false memory may have been created.

\section{Conclusion}

Amy's case exemplifies a paradigmatic healing process in its context, severity, life-threatening consequence, and ultimate successful resolution. Her detailed narrative account accords well with preliminary research findings on what other recovered bulimics believe facilitated their recovery. Yet with the advent of Amy's recall of her NDE, another dimension was added to her recovery process, which highlights the single most important factor that helped her heal. Her NDE's teaching about the responsibility of choice was crucial to her recovery. Moreover, insights accessed during nonordinary, altered states potentially reverberate throughout the individual psyche, and beyond. Thus Amy's NDE still had an effect without her conscious awareness, and her insights may further strike a chord with other bulimics not yet in recovery. As first-hand sources regarding the nature of eating disorders, the stories of Amy and other recovered bulimics may prove to have clinical efficacy in helping teach bulimics that they ultimately have the freedom of choice and the power to regulate internal state changes through other means.

\section{References}

Colli, J. E. (2003, January). Victims no longer: Healing chronic abuse in the context of near-death experiences. Paper presented at the 14th Annual Conference of the International Association for Near-Death Studies, Honolulu, HI.

Field, A. E., Herzog, D. B., Keller, M. B., West, J., Nussbaum, K., and Colditz, G. A. (1997). Distinguishing recovery from remission in a cohort of bulimic women: How should asymptomatic periods be described? Journal of Clinical Epidemiology, 50, $1339-1345$.

Greyson, B. (1983). The Near-Death Experience Scale: Construction, reliability, and validity. Journal of Nervous and Mental Disease, 171, 369-375.

Greyson, B. (1986). Incidence of near-death experiences following attempted suicide. Suicide and Life Threatening Behavior, 16, 40-5.

Greyson, B. (2001). Posttraumatic stress symptoms following near-death experiences. American Journal of Orthopsychiatry, 71, 368-373.

Grof, S., and Grof, C. (1989). Spiritual emergency: When personal transformation becomes a crisis. New York, NY: Putnam's. 
Groth-Marnat, G., and Summers, R. (1998). Altered beliefs, attitudes, and behaviors following near-death experiences. Journal of Humanistic Psychology, 38, 110-125.

Hall, R. C., Hoffman, R. S., Beresford, T. P., and Wooley, B. (1989). Physical illness encountered in patients with eating disorders. Psychosomatics, 30, 174-191.

Harman, W., and Rheingold, H. (1984). Higher creativity: Liberating the unconscious for breakthrough insights. Los Angeles, CA: Tarcher.

Hay, P. J., Gilchrist, P. N., Ben-Tovim, D. I., Kalucy, R. S., and Walker, M. K. (1998). Eating disorders revisited. II: Bulimia nervosa and related syndromes. Medical Journal of Australia, 169, 488-491.

Herzog, D. B., Sacks, N. R., Keller, M. B., Lavori, P. W., von Ranson, K. B., and Gray, H. M. (1993). Patterns and predictors of recovery in anorexia nervosa and bulimia nervosa. Journal of American Academy of Child and Adolescent Psychiatry, 32, 835-842.

Holden, J. M. (1996). Effect on emotional well-being of hypnotic recall of the near-death experience. Journal of Near-Death Studies, 14, 273-280.

Holden, J. M., and MacHovec, F. (1993). Risk management in hypnotic recall of neardeath experiences. American Journal of Clinical Hypnosis, 36, 38-46.

Irwin, H. J. (1993). The near-death experience as a dissociative phenomenon: An empirical assessment. Journal of Near-Death Studies, 12, 95-103.

Jarman, M., and Walsh, S. (1999). Evaluating recovery from anorexia nervosa and bulimia nervosa: Integrating lessons learned from research and clinical practice. Clinical Psychology Review, 19, 773-788.

Miller, M. D. (1993). Therapeutic effects of a near-death experience in anorexia nervosa. Adolescent Psychiatry, 19, 489-501.

Morgan, J. S. (1988). Female identity and eating disorders: Etiology, treatment and recovery. Unpublished doctoral dissertation, Duke University, Durham, NC.

Reas, D. L., Williamson, D. A., Martin, C. K., and Zucker N. L. (2000). Duration of illness predicts outcome for bulimia nervosa: A long-term follow-up study. International Journal of Eating Disorders, 27, 428-434.

Ring, K. (1991). Amazing grace: The near-death experience as a compensatory gift. Journal of Near-Death Studies, 10, 11-39.

Ring, K. (1992). The Omega Project: Near-death experiences, UFO encounters, and mind at large. New York, NY: William Morrow.

Rorty, M., and Yager, J. (1996). Histories of childhood trauma and complex posttraumatic sequelae in women with eating disorders. Psychiatric Clinic North America, 19, 773-91.

Rorty, M., Yager, J., and Rossotto, E. (1993). Why and how do women recover from bulimia nervosa? The subjective appraisals of forty women recovered for a year or more. International Journal of Eating Disorders, 14, 249-260.

Saito, S., Kita, K., Morioka, C. Y., and Watanabe, A. (1999). Rapid recovery from anorexia nervosa after a life-threatening episode with severe thrombocytopenia: Report of three cases. International Journal of Eating Disorders, 25, 113-8.

van der Kolk, B. A. (Speaker). (1995). The psychological and biological processing of traumatic memories (Cassette Recording, September 29). Seattle, WA: XYZ Audio.

van der Kolk, B. A. (1996). Trauma and memory. In B. A. van der Kolk, A. C. McFarlane, and L. Weisaeth, (Eds.), Traumatic stress: The effects of overwhelming experience on mind, body and society (pp. 279-302). New York, NY: Guilford.

van der Kolk, B. A. (1999, October). Understanding the impact of trauma. Paper presented at the 8th annual conference of Family and Addiction Conferences and Educational Seminars, Seattle, WA.

van der Kolk, B. A., Perry, J. C., and Herman, J. L. (1991). Childhood origins of selfdestructive behavior. American Journal of Psychiatry 148, 1665-71.

Viesselman, J. O., and Roig, M. (1985). Depression and suicidality in eating disorders. Journal of Clinical Psychiatry, 46, 118-124. 